\title{
Erratum to: Electrodeposition of 4,4'-di-tert-butylbiphenyl peroxide from the anodic oxidation of $p$-tert-butylphenol in an alkaline acetonitrile solution
}

\author{
Maali Abidi ${ }^{1,2}$ - Najoua Derbel ${ }^{3}$ Rihab Hkiri ${ }^{3}$ - Hasen Mohamed Sbihi ${ }^{4}$. \\ Hechmi Said $^{1} \cdot$ Emilia Morallon $^{2} \cdot$ Salma Besbes-Hentati $^{1}$
}

Published online: 18 March 2017

(C) Springer Science+Business Media Dordrecht 2017

\section{Erratum to: J Appl Electrochem}

DOI 10.1007/s10800-016-1041-2

In the original publication of the article, the $\mathrm{X}$-axis of the Fig. 5c (XPS spectra) should be Binding energy instead of Bending energy. The correct version of the Fig. 5 is provided in this erratum and the original version was also corrected.

The online version of the original article can be found under doi:10.1007/s10800-016-1041-2.

Salma Besbes-Hentati salma.hentati@fsb.rnu.tn

1 Laboratory of Chemistry of Materials, Faculty of Sciences of Bizerte, University of Carthage, Bizerte, Tunisia

2 Department of Physical Chemistry, Institute of Materials, University of Alicante, Alacant, Spain

3 Laboratory of Spectroscopy Atomic and Molecular, University of Tunis-El Manar, Tunis, Tunisia

4 Chemistry Department, College of Science, King Saud University, P.O. Box 2454, Riyadh 1145, Saudi Arabia 


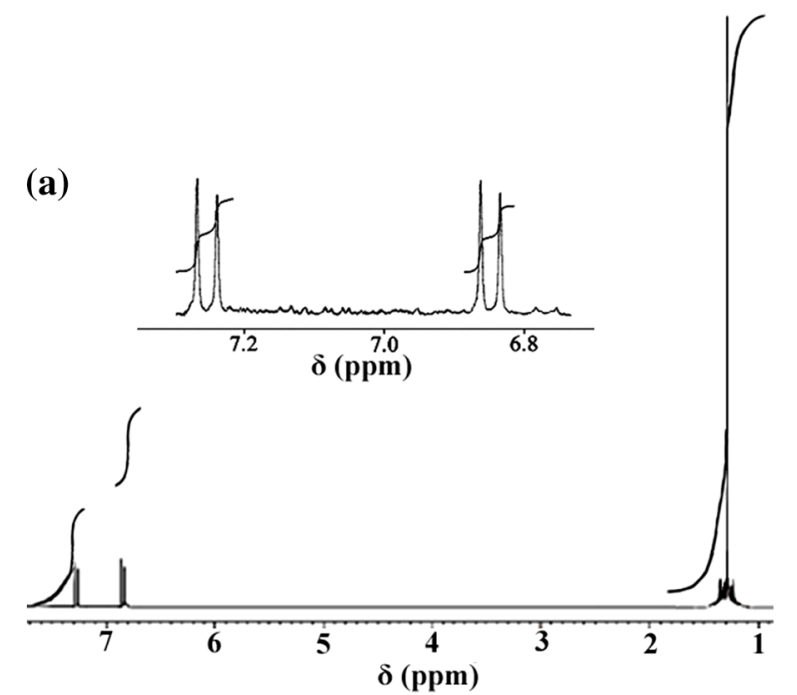

(b)

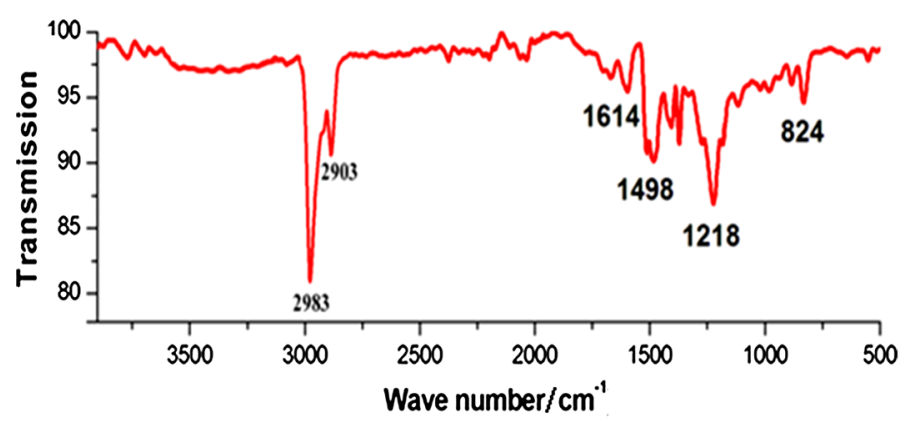

(c)
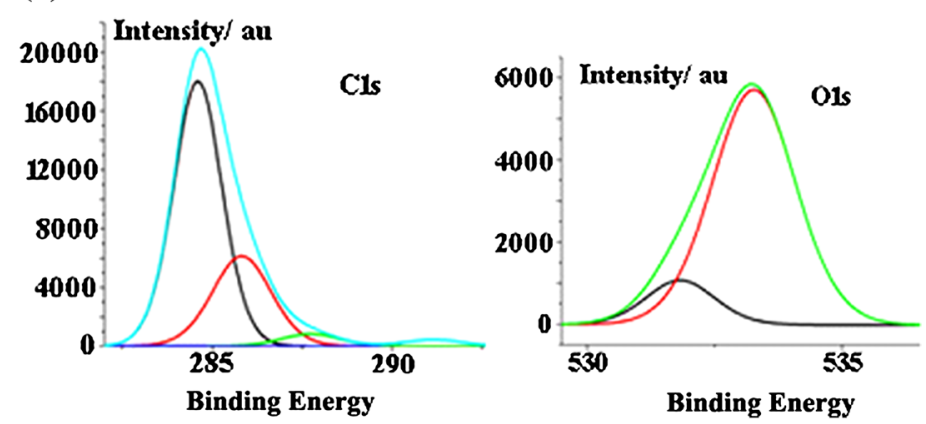

Fig. $5 \mathrm{HNMR}$ in $\mathrm{CD}_{2} \mathrm{Cl}_{2}(\mathbf{a})$, FTIR (b) and XPS spectra (c) of 2 